\title{
Pilot Study: evaluation of the efficacy of homeopathic anti-tumor protocols in Ehrlich tumor
}

\author{
Juliana Gimenez Amaral, Elizabeth Peres Hurtado, Thayná Neves Cardoso, \\ Mariana Petrillo, Aloísio Carvalho, Leoni Villano Bonamin
}

\author{
Universidade Paulista, São Paulo, Brasil.
}

Cancer is the second leading cause of death worldwide, with breast cancer one of the tumors with the highest incidence in Brazil, with an estimated 57,120 new cases in 2014. Several forms of treatment and control of cancer symptoms has been studied, among them homeopathy. In the Banerji clinic in India, doctors have used a protocol consisting of 4 homeopathic medicines with relevant results that motivated this study. In our research the Ehrlich tumor was used, a transplantable tumor cell, whose features are similar a breast carcinoma, as discovered in 1905 by Paul Ehrlich. Objective: To analyze the clinical and immunomodulatory Ehrlich tumor in mice treated with the homeopathic medications found in the Banerji Protocol and with thymulin 5CH. Methodology: The project was approved under protocol 158/13 of the Paulista University Ethics Committee. BALB / c mice between 6 and 9 weeks old were used. Each mouse was inoculated with $1 \times 107$ tumor cells into the peritoneum cavity, to obtain the ascitic form of tumor. Mice were divided in 5 groups ( $\mathrm{N}=6$ animals per group), being the following treatments: control treated with sterile water, Conium maculatum 200CH, Thuja occidentalis $200 \mathrm{CH}$, Phytolacca decandra $200 \mathrm{CH}$, Carcinosinum 200CH, every day being $0.1 \mathrm{~mL} / 10 \mathrm{~g}$ body weight. The animals were weighed and the consumption of water and feed was measured daily. Clinical signals and body temperature were also registered daily. The survival of each group was also analyzed. Results: All groups presented reduction of body temperature one day before death. The peak of clinical symptoms in the majority of groups was in the D18, while Carcinosinum treated group had its peak in D29. The observed clinical symptoms were apathy, prostration, cyanosis, priapism, tachydyspnea, genital edema and secretion, decreased general activity, hair bristling and trembling. The control group had loose stools as unique symptom, seen in $20 \%$ of mice; the Carcinosinum treated group showed trembling as the sole symptom, that affected $20 \%$ of mice. The group treated with Conium maculatum showed higher incidence of clinical symptoms, involving up to $80 \%$ of mice, while the group treated with Carcinosinum showed lower incidence of clinical symptoms, affecting no more than $40 \%$ of mice, with weight reduction (reduction of ascites) and longer survival, when compared to the other groups. Conclusion: The results of the pilot study directed us to the second stage of the research, in which the histopathological and immunohistochemical observation will be assessed, being Carcinosinum the treatment chosen to this next step.

Keywords: cancer, high dilutions, Ehrlich tumor, Banerji Protocol

(c)) EY-NC-ND Licensed to GIRI

Support: authors declare that this study received no funding

Conflict of interest: authors declare there is no conflict of interest

Received: March 30th 2014; Revised: May 10 th 2014; Published: June 30 2014.

Correspondence author: Juliana Gimenez Amaral. jugi.amaral@yahoo.com.br

How to cite this article: Amaral JG, Hurtado EP, Cardoso TN, Petrillo M, Carvalho A, Bonamin LV. Pilot Study: Evaluation of the efficacy of homeopathic anti-tumor protocols in Ehrlich tumor. Int J High Dilution Res [online]. 2014 
Int $J$ High Dilution Res 2014; 13(47):143-143

[cited YYYY Month dd]; 13(47):143-143. Proceedings of the XXVIII GIRI Symposium; 2014 Jun 20-22; Sighisoara (Romania). GIRI; 2014; Available from: http://www.feg.unesp.br/ ojs/index.php/ijhdr/article/view/749/723 